\title{
Vegetation dynamics and plant constraints: separating generalities and specifics
}

\author{
R. van Hulst
}

Department of Biological Sciences, Bishop's University, Lennoxville,Quebec, Canada J1M 1 Z7.
E-mail: rvhulst@ubishops.ca

Keywords: Constraints, Scaling, Succession, Trade-offs, Vegetation dynamics.

\begin{abstract}
Vegetation dynamics is a stochastic process of species replacement after disturbance. It occurs because individual species are limited by general constraints and trade-offs. As these constraints and trade-offs are becoming better known, we understand more about the relationships between disturbance dynamics, species pools, and vegetation dynamics. This paper provides a summary of recent work on plant scaling and ecological trade-offs, and explores its implications for vegetation dynamics. Those aspects of succession that are predictable - given the local species complement - can be understood as consequences of these general patterns and constraints. Several are explored in this paper. The inherently stochastic nature of the process derives from the disturbance dynamics that forces it, from the sampling processes that are responsible for selecting potential invaders, and from the chance processes involved in species interactions. The dynamics of species that invade established communities is the least understood but potentially the most crucial aspect of vegetation dynamics. The relation of community invasion to gap creation and to scaling constraints is briefly discussed.
\end{abstract}

Abbreviation: RGR - Relative growth rate.

\section{Introduction}

Changes in vegetation over lengths of time too short for evolution to change species, but too long for single population dynamics to be relevant, are both ubiquitous and difficult to study in any detail. The most casual observer of nature is familiar with the procession of species replacing one another after a major disturbance. The study of this phenomenon by ecologists has traditionally been one of the major battlegrounds for adherents to different ecological persuasions (see McIntosh 1999, for a recent review). To those who consider a community to be relatively integrated and fixed, succession is a communitylevel phenomenon (Clements 1916, Odum 1953). To the adherents of an individualistic concept of vegetation (Gleason 1926, 1927), succession is a process of species replacement, rather than community replacement. Ecologists of all persuasions have been busy trying to find appropriate descriptors of the process, from community change through species change in multivariate speciesspace (Orlóci and Orlóci 1988), via changes in community rank-abundance curves (Bazzaz 1975), to community invasibility and potential to invade of species (van Hulst 1988).

The focus on communities has not been very useful: communities are abstract entities defined in terms of species composition of dominants, physiognomy, and constancy. However, when species composition and physiognomy change, the defining characteristics of the communities change also, thereby forcing us to deal with species behavior once again. To focus on the species might be useful if we had full information on the biology of each species - something that is not usually the case. Furthermore, even if such information were available, it is doubtful that we would be able to handle all of it in a useful model. In short, neither of these approaches has done much to deepen our insight into what changes are characteristic for all forms of succession, no matter what species and what communities are involved.

It is also becoming clear that communities are too much the products of chance factors to ever allow precise prediction of particulars (Drury 1998). This suggests that we should first attempt to obtain order of magnitude type 
predictions of general species characteristics, and only once we can make these successfully, go on to tackle more detailed predictions. The domain of biological scaling laws (allometry) is concerned with just such predictions (Niklas 1994, Enquist et al. 1999). Recent progress in this field, as well as an increased understanding of biological trade-offs (Bazzaz 1996) and resource allocation (Bazzaz and Grace 1997), open the prospect of a general theory of vegetation dynamics. Such a theory may be useful even if we lack a detailed knowledge of the particulars of a site and the natural history of all species involved. It is the aim of this paper to sketch such a theory.

Succession is difficult to study for the obvious reasons that it is slow and typically involves many species - different ones in different areas, and because it occurs at the poorly understood interface between the species and the community. Nevertheless, the last twenty years have seen major progress in understanding the species-level constraints and trade-offs that lead to a more-or-less predictable pattern of community replacement in succession. These constraints and trade-offs are often fundamental and apply to all plants. They can therefore be understood in a strict evolutionary framework, something that was notably missing from early theorizing on succession (Drury and Nisbet 1973).

What exactly is predictable about succession? For someone who knows the local species complement, the species appear after a disturbance in a more-or-less fixed order. This order is a function of the species that are capable of reaching a disturbed site (local species complement, dispersal), the nature of the disturbance, and the general constraints on plant species. These constraints arise because of scaling laws and trade-offs. It is these laws, I will argue, that permit a general insight into the phenomenon. To develop such an insight is of great practical and theoretical importance, especially now that disturbances of natural vegetation are becoming ever more frequent (Vitousek 1994).

The aim of this paper is to show how new insights into plant scaling lead to effective explanations of a number of successional phenomena. However, I will also argue that too little attention has been devoted to the relationship between site disturbance regimes and vegetation dynamics, and I will attempt to remedy this here.

\section{Disturbance regimes}

Disturbance is defined here as any process that destroys vegetation, whether by abiotic or biotic means. In first approximation, two main features characterize the disturbance regime of a site: the frequency of disturbances

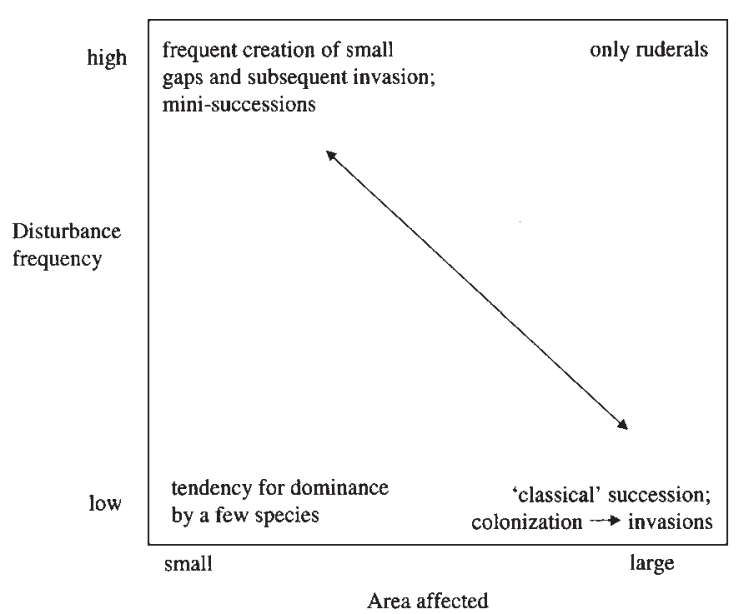

Figure 1. Vegetation change as a function of disturbance frequency and disturbance extent.

and the average area disturbed. These two dimensions of variation give rise to a range of disturbance regimes (Fig. 1). Along the main diagonal are the sites that are frequently disturbed by small disturbances on one end, and sites that are rarely disturbed by large disturbances at the other. This range of disturbance regimes determines the main range of vegetation dynamics, from frequent minisuccessions to classical succession. Off this diagonal we find relatively uninteresting situations, with either dominance by a few super-competitors or dominance by a few ruderals. What complicates this simple picture is that because different species reach different sizes at maturity, the relevant spatial scales can be quite different. The same site may experience frequent small disturbances, as well as experiencing the odd large-scale disturbance. The implications of these disturbances for different plant species can be quite different.

While this division allows us to differentiate between some important categories of vegetation change, it is obvious that both disturbance frequency and disturbance extent are scale dependent and need to be defined relative to the longevity and size of the species affected. Let us therefore define a disturbance frequency of greater than one during the lifetime of the dominant species as 'high', and less than 0.01 during the lifetime as 'low'. Similarly, define a disturbance that affects only areas smaller in size than those occupied by average adult dominants, as 'small'. If the area affected is larger than the area occupied by 100 individuals, call it 'large'.

Further subdivisions of disturbance categories may be desirable. For example, disturbances that eliminate all plant propagules give rise to 'primary' successions in which all propagules must arrive anew. Some forms of 
disturbance favor certain species: fire, for example, is a sufficiently regular form of disturbance in certain ecosystems that fire-adapted species have evolved there (Bond and van Wilgen 1996). Similarly, evolution of species to any form of disturbance can be expected if that disturbance is 'predictable' and of sufficiently regular occurrence.

The most important feature of disturbance is how common it is in an environment - provided that common is defined appropriately, i.e., on a time scale of the same order of magnitude as the longevity of the dominant organisms. Even forests, those bulwarks of permanence, are buffeted by disturbances that are rare and large in terms of human experience, but common and small on the time and spatial scales of their dominant species (Drury 1998, Chambers et al. 1998).

Because the frequency distributions of disturbances and of the sizes of disturbances are both skewed to the right, small and frequent disturbances predominate in most sites (White and Pickett 1985). Most vegetation dynamic action therefore takes place in the upper left corner of Figure 1, and it is appropriate to concentrate on this in subsequent sections.

\section{Local species complement}

Some regions have a large pool of species from which colonizers and invaders are sampled. In other regions, this pool is small. The most spectacular examples of colonization or invasion by novel species involve species that were introduced by humans, intentionally or not. Often, the species that did become established, share some combination of ecological factors (involving the lack of local enemies or the ability to profit from disturbance, or some other feature). In a subsequent section, I discuss invasion of existing communities. Here, the factor that interests us is simply the size and nature of the pool from which potential colonizers and invaders are sampled. Often, this pool will be fairly well-known, but in areas where the local flora and fauna are poorly known, floristic uncertainty will add to the uncertainty that surrounds vegetation dynamics. Sampling from the local pool of species will rarely be at random (Begon et al. 1996), and constitutes a second intrusion of chance events in the successional process.

\section{Dispersal}

Neither empty habitats nor invasable communities are reliably present, but the dispersal patterns of some species seem optimally adjusted to find just such habitats and communities (Begon et al. 1996). Species that produce many light and widely dispersed seeds are at a disadvantage when they try to invade an existing, closed community. However, such seeds are often likely to arrive first after a major disturbance, when local seed producers have been removed. The trade-off between seed number and seed size is one of the driving forces of vegetation dynamics and is discussed further below. Seeds that normally germinate in open gaps do not need to carry large amounts of reserve food, but those that germinate in established vegetation on a thick layer of litter do (Westoby et al. 1992, Kimmins 1997).

On the other hand, plants that colonize disturbed habitats typically produce as many small seeds as possible, because the chances that any seed will be dispersed to an appropriate disturbed site are also small. Environments that are subject to repeated disturbance typically have many species that produce small, easily dispersed seeds (Silvertown and Lovett Doust 1993). Sometimes recently disturbed sites can be most easily found by 'hitching a ride' with animals that frequent such sites (Stiles 1992).

Recent work on seed dispersal patterns in forests (Clark et al. 1999) offers some hope that both short and long range seed dispersal of many species can be predicted. It also suggests that past models of seed dispersal have tended to underestimate long range spread following environmental change.

Dispersal in time can also be very effective (Silvertown and Lovett Doust 1993). In plants, this takes two forms: dormancy and suspended development. Sites that have an average inter-disturbance time shorter than the longevity of buried dormant seeds are almost always colonized first by such seeds. Suspended development is especially common in forests, where some species form 'oskars', suppressed juveniles that can spend many years waiting for a gap in the canopy without doing much growing (Silvertown and Lovett Doust 1993). Such dispersal in time allows a long period of collection of rare dispersal elements, something that is especially important if the average time between disturbances is long compared to the rate of expected arrival of these dispersal elements.

Dispersal also is strictly a function of what propagules are locally available. It therefore involves both particular site factors and the vagaries of geography and history. This leads to a strong asymmetry in ecology between presence (a species can grow in a site) and absence (a species may be absent for many reasons).

The importance of dispersal in vegetation dynamics is subject to experimental verification: seeds or other propagules can be experimentally planted, and their fate can be studied (van Hulst 1997). Since successful disper- 
sal to a site is essential for subsequent growth, dispersal forms the first step of vegetation change.

\section{Clonal propagation}

Growth into small gaps often occurs clonally. A small gap in a forest (smaller than, say, one-tenth the area of a typical adult tree) is readily filled by the neighboring trees. The same phenomenon occurs in many other vegetation types. The advantage that accrues to already established individuals growing into gaps is caused by the much greater reserves such individuals can generally rely on compared to those that are present in a seed. Plants, as modular organisms, are uniquely able to profit from this.

Clonal exploration and propagation generally represent a very effective means for plants to harvest local or temporally variable resources. In Figure 1 these conditions prevail in the upper left hand corner of the diagram. The small extent of most disturbances makes clonal filling of gaps possible, and the relatively long time between major disturbances allows long lived plants to grow (Bazzaz 1996).

Clonal propagation is also important in spatially very diverse environments, and represent a way for plants to utilize such an environment by effectively averaging local conditions. Spatial diversity may have been present in the environment even before the arrival of the plants in question. Often, however, it is at least in part biotically caused: small initial spatial differences that resulted from chance factors become entrenched and are often enlarged.

\section{What combinations of traits are possible: scaling, constraints, and trade-offs}

The ideal plant produces many large seeds, it starts producing these when it is only a few weeks old, and continues to do so for many centuries. It grows fifty meters high within one growing season, and has small, thick, evergreen leaves loaded with anti-herbivore defenses that it keeps for many years. However, its leaves are also very efficient in photosynthesis. It has a very high growth rate, both in open and shaded environments...

If such a plant existed, it would be the only kind of plant found in any environment (and there would be no large animals around either). But, of course, such a plant would be impossible. In this section, we will ask why.

Long-lived plants (and animals) invariably have low relative growth rates (RGR, the rate of growth on a per unit biomass basis; Charnov 1993, Stearns 1992). Plants that differ enormously in their growth rates and their longevities often do attain similar adult sizes (Enquist et al.
1999), they just vary in the time they take to do so. Such life history differences, and many other ones, reflect differences in the patterns of resource allocation between different species. Arguably the most important resource for a plant is biomass or carbon, because most other required resources can be acquired with carbon (Poorter and Villar 1997).

We now know that the metabolic rate $B$ of both animals and plants scales as the 3/4 power of above-ground body mass $M$ (West et al. 1997, 1999), and this for essentially identical reasons. Both plants and animals must obtain resources from their environment through surfaces, and distribute these resources to their tissues through a system of pipes. Some reasonable assumptions about these pipes lead to the general scaling law $B=M^{3 / 4}$ (West et al. 1997, Enquist et al. 1999).

The implications of this are considerable: the metabolic rate (and other rates that are related to it, such as the maximum relative growth rate) must fall further and further behind body mass, as the latter increases. This is true for animals as well as plants, but plants are stationary when adult, and they compete with other plants for light, water, and dissolved substances. This is unlike the situation in mobile animals that can actively forage. In plants, competition is generally won by the plant with the highest leaves, or the most widespread or deepest roots. Having high leaves implies having long stems to support them, and having deep roots implies having long roots. Both of these require a large body mass, and large body mass is associated with relatively low metabolic rate. Unfortunately, to attain a large body mass fast a plant must have an extra large metabolic rate, especially in competitive situations, where time is of the essence, and in heavily disturbed sites, where the time between disturbances is short.

This leads to an interesting (and well-known) phenomenon: the first plants to colonize a disturbed area are typically fast growing weedy species of small stature. Initially, most competition such plants face is intraspecific, but eventually they are outcompeted by even taller, but more slowly growing plants. This continues until a limit set by two factors of the local environment: the resources available, and the time until the next disturbance. This gradual replacement of small, quick growers (and quick reproducers) by large, slow growers is a universal characteristic of most vegetation dynamics.

Of course, this assumes that the density of all plants is the same, which is definitely not the case: woody plants generally have greater density than herbaceous ones (Niklas 1994, 1997), and within woody plants there are also pronounced differences. For example, the wood of pop- 
lars is less dense than that of oaks. Low density for a tall plant increases the risk of buckling and breakage, and is only seen in relatively short-lived trees (Niklas 1994). Poplars are much shorter lived than oaks, and the risk of a killing storm increases with time of exposure.

The maximum mean weight that is reached by competing plants (or animals) is proportional to their density to the power $-4 / 3$, no matter whether competition is intraor interspecific (the famous, and misnamed ' $-3 / 2$ thinning law', see Enquist et al. 1998). The total energy that is available to plants in an area must be proportional to $M^{0}$, that is constant (the maximum plant population density $N_{\text {max }} \propto M^{3 / 4}$, so eventually the rate of resource use per unit area will become $M^{3 / 4} \bullet M^{3 / 4}$; Enquist et al. 1998). Or, stated differently, total energy use (productivity) is independent of body size. This principle of 'energy equivalence', valid for both plants and animals, is probably the most basic finding in ecology over the last decade, and it also has far-reaching implications for our understanding of successional vegetation change.

If productivity is independent of body size, why are all plants not the size of mosses? The answer, of course, lies in the competititive advantage of the tall. Why are all plants not big trees? Because many environments are disturbed too frequently to allow for the growth of tall and long-lived species. Where we see further differentiation between species is in the ways they capture and deploy their resources. The environment determines what resources are most critical to a growing plant, and in general the plant will allocate its resources so as to maintain maximal growth. This can usually be accomplished by simply keeping internal pools of critical products at constant levels (Lambers et al. 1998). The only use of a plant's resources that ultimately matters, evolutionarily speaking, is the production of as many viable offspring as possible. How best to achieve this depends on the ecological conditions. In relatively constant (or at least predictable) environments, this may be best accomplished by clonal reproduction. In environments where water is limiting, maximum allocation to roots is optimal. Light capture is important for photosynthesis, all the more so where an increased allocation to leaves, shoots, or rubisco (ribulose biphosphate carboxylase/oxygenase, the main constraint on $\mathrm{CO}_{2}$-uptake in most plants) pays off in terms of increased carbon for the plant. If minerals are scarce, heavier root investment may be indicated, or carbon investment to support symbiotic Rhizobium bacteria or to sustain mycorrhizae. Defense against herbivores or pathogens (Loehle 1988) may require a substantial investment of carbon (and other resources), and competition with other plants may require the 'luxury uptake' of min- erals which are not yet required, but will be in the future. Storage of carbon, finally, may be beneficial because of environmental constraints.

All these competing demands on a finite pool of carbon need to be reconciled, and the optimal allocation will depend on details of the environment and the constraints that the plant is under (Bazzaz 1997, Chapin 1993, Gleeson and Tilman 1994). What interests us here is the way in which optimal allocation strategies shift as the successional environment changes. One simple idea is Tilman's suggestion that many successions reflect a shift from communities limited by nitrate to communities limited by light (Tilman 1988). This certainly is an important shift in most primary and some secondary successions, but even more important and more general is the shift from small to large sized plants.

Growth rate, for example, depends (understandably) on local light conditions, but differently for different species and also differently through the life of a plant. Often, however, species which are fast growing under low-light conditions are also fast-growing under high light conditions (Poorter 1999, Poorter and Werger 1999). Plant species that are usually exposed to high light levels vary in relative growth rate as a function of physiological and morphological differences. The physiological differences are chiefly associated with net assimilation rate (NAR; Poorter 1999, Körner 1991), while morphological differences are related to light intensity and evaporation (leaf area ratio, density, size, and opening characteristics of stomata; Lambers et al. 1998).

Leaf size and leaf photosynthetic rate, however, are both independent of plant mass (Brown and West 2000). Leaf size is related to thermal load: small leaves have a thinner boundary layer and maintain lower temperatures in hot and open conditions (Lambers et al. 1998). Under high light conditions, leaves with a thick mesophyll layer are also more effective than thin leaves (Lambers et al. 1998), with the result that such leaves are common in early successional habitats. Thick leaves are generally more durable than thinner leaves, and they require a longer productive period to make up for their construction costs. In most habitats this long pay-back period requires the leaves to be protected from herbivores, and the incorporation of protective chemicals lengthens their pay-back time even more. Unfortunately, photosynthetic efficiency of a leaf also decreases with leaf thickness and leaf age, making such leaves less efficient than larger, thinner leaves (Lambers et al. 1998). Similar trade-offs exist between growth rate and woodiness (essential for tall plants, see Poorter and Villar 1997, Sibly and Vincent 1997), between growth and defense (Lerdau and Gershenzon 
1997), between reproduction and growth (Reekie 1997), and between a host of other plant traits.

The ubiquity of such trade-offs means that what is optimal for the plant is very dependent on local conditions, and on what other species, competitors, herbivores, pathogens are present. From an evolutionary perspective, adaptation to local physico-chemical conditions is less troublesome, as long as they remain constant over evolutionary time. Adaptation to biotic conditions, conversely, often leads to never ending spirals of adaptation and counter-adaptation (Begon et al. 1996), and to a proliferation of alternative species.

\section{Species invasions}

Succession involves colonization of newly disturbed habitats, as well as invasion into existing communities. What makes a community invasable? What makes a species a good invader? These are important questions in a world in which many non-native species accompany humans in their travels (Lodge 1993). However, it is first necessary to differentiate between species invasion at a global level and invasion at a local level. At the global level, invasion studies are concerned with how successful an alien species is in a local community. It is not easy to compare the invasiveness of different species and the invasibility of different communities, because unavoidably these factors become confounded with species, community, and locality differences (Lonsdale 1999). However, invasion is also a local process, where a species that is not necessarily alien but was hitherto not present at a site becomes part of a community (van Hulst 1988). Thus, 'invasive' species are not necessarily aliens.

What governs whether a species is a good invader? This question cannot be answered without considering the community being invaded (Lodge 1993). Similarly, the question, 'What makes a community resistant to invasion?', can only be answered in relation to a specific invader. Good invaders are often species that have a high relative growth rate and high plasticity (Hengeveld 1989, Levine and D'Antonio 1999), but some correlative evidence suggests otherwise (Lawton and Brown 1986). Invaders also rely often on disturbance to gain a foothold in a community, and, as we saw above, there exists a continuum of disturbances both in terms of scale and frequency. Moreover, the process of invasion is inherently a stochastic one, in terms of sampling from a pool of potential invaders, early establishment, and interactions with already established plants. We therefore cannot predict the outcome of any particular invasion event, but can only say something about the process in general. Tilman (1999) has pointed out that the lower levels of available resources that are a consequence (or a cause?) of greater diversity also make a community less susceptible to invasion. This suggests that the slowing down of the rate at which new species become established after a disturbance is a consequence not only of a 'sampling effect' (fewer and fewer new species available for invasion), but also of diminishing resource availability. Experiments are required to test these ideas.

\section{Synthesis: Do we understand succession?}

The vegetation changes that occur after a disturbance support few generalizations, in spite of many attempts at finding them (Grime 1977, Miles 1979, McIntosh 1999). In part, this is no doubt because generalizations have been sought in the wrong places, at the community level or at the level of particular species. Researchers also have underestimated the extent to which actual successions are influenced by historical contingencies (Bazzaz 1996). It now appears that what generalizations can be made about the process are all related to general scaling laws, biological constraints, and specific trade-offs. As with all processes that incorporate a substantial stochastic component, prediction in specific cases of vegetation dynamics will have to be in terms of probabilities, and it will always be easier to explain successional phenomena after they have occurred than to predict them.

Two critical features of a habitat are the distribution of times between disturbances and the sizes of these disturbances. Both must be measured on a time scale appropriate for the organisms that might inhabit that habitat. In habitats where the expected time between disturbances is short, and the expected size of a disturbance is large, organisms have to grow rapidly. Even where the expected time between disturbances is long, the first colonizers after a disturbance will be fast growing plants, because plants that are well represented in the seed rain are rapid growers adapted to disturbed habitats. Fast growth rate and large size are incompatible, so early successional plants will generally be of small stature. The only exceptions to this appear to be several fast growing tree species that also are very fragile - trees that clearly have tradedoff sturdiness against fast growth.

If light, water, and minerals are present in excess, then early colonizers will be fast growing, weedy plants or ruderals. If light or water are limiting, then growth will be less spectacular, for the resource shortage will depress the maximum metabolic rate. Adaptations to enhance photosynthesis under low light and to conserve water are energetically costly (Lambers et al. 1998). If mineral nutrients are limiting, as is often the case in primary succession, then fast growth is prevented by a combination of the lack 

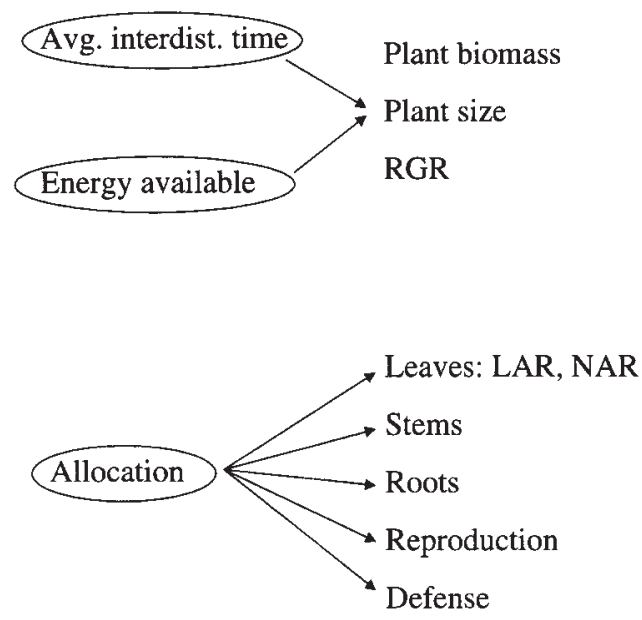

Figure 2. Succession as a function of average interdisturbance time and energy available, which set limits to plant biomass, size, and relative growth rate (RGR). Resources are then channeled by the plant in such a way as to keep internal concentrations as constant as possible. This generally guarantees an allocation of resources that optimizes growth and reproduction in an unpredictable environment, but within the constraints set by the plants' ecological adaptations.

of mineral resources and reduced photosynthesis resulting from a shift of resources to roots (Lambers et al. 1998).

With a plant cover, however sparse, some conditions may ameliorate (organic matter in the soil, nutrients available, shelter), while others can only deteriorate (more interspecific competition, in particular less light). If a major disturbance does not occur, there will be a gradual shift toward larger (and therefore more competitive) and longer lived plants. These must also have lower metabolic rates and therefore lower growth rates. This is not a problem in habitats where major disturbances are infrequent. Here, we see not only to a shift toward larger plant size, but also a proliferation of strategies to make optimal use of an increasingly complex habitat.

Plants have to deal with many problems that are related to their relative immobility, at least after the seed stage. One of the most serious of these is the fact that, when growing up, a plant can increase in size by many orders of magnitude (almost twelve in the case of a sequoia tree, West et al. 1999). Some traits are sufficiently plastic that a plant can change them during ontogeny (sun and shade leaves are a classic example). Other traits are species specific: RGR $\max$ (Poorter 1999), the arrangement of branches and leaves in a tree (Horn 1971), and the location of meristems (Boggs 1997). As a plant matures it must deal with many different environments, only some of which it can adjust to. The environment is experienced by a plant in an extremely fine-grained way, especially as plant-induced environmental differences proliferate during succession.

The view of succession that emerges is one centered on disturbance: the absence of a major disturbance for some time enables different species with increasingly long lifetimes, and of increasing size, to proliferate. These species also are increasingly specialized to a variety of conditions that are largely plant-induced. In many environments, this process of invasion of new species may be halted (perhaps temporarily so) by space or resource preemption by dominants. Small disturbances are generally sufficient to prevent this from happening, and such disturbances are common in many habitats (Bazzaz 1996). The energy available at a site greatly constrains the size, longevity, maximum growth rate, and number of species that can colonize or invade. It is therefore appropriate to use two key variables, time between disturbances and energy available, in a scheme that summarizes different forms of succession (Figure 2). While the diagram can summarize some features of succession, its main shortcoming is that it focuses on colonization, but completely neglects the process of invasion and its counterpart, dominance by existing species. Much remains to be studied in this field, and experimental interference with existing systems looks particularly promising.

\section{References}

Bazzaz, F.A. 1975. Plant species diversity in old-field successional ecosystems in southern Illinois. Ecology 56: 465-488.

Bazzaz, F.A. 1996. Plants in Changing Environments. Cambridge Univ. Press, Cambridge.

Bazzaz, F.A. 1997. Allocation of resources in plants: state of the science and critical questions. In: F. A. Bazzaz and J. Grace (eds.), Plant Resource Allocation. Academic Press, San Diego. pp. 1-37.

Bazazz, F.A. and J. Grace. (eds.) 1997. Plant Resource Allocation. Academic Press, New York

Begon, M., J.L. Harper and C.L. Townsend. 1996. Ecology: Individuals, Populations and Communities. $3^{\text {rd }}$. Blackwell, Oxford.

Boggs, C.A. 1997. Resource allocation in variable environments. In: F. A. Bazzaz and J. Grace (eds.), Plant Resource Allocation. Academic Press, San Diego. pp. 73-92.

Bond, W.J. and B.S. van Wilgen. 1996. Fire and Plants. Chapman and Hall, London.

Brown, J.H. and G.B. West (eds.). 2000. Scaling in Biology. Oxford Univ. Press, Oxford.

Chapin, F.S. 1993. Functional role of growth forms in ecosystem and global processes. In: J. R. Ehleringer and C.B. Field (eds.), Scaling Physiological Processes. Academic Press, San Diego. pp. 287-312.

Chambers, J.Q., N. Higuchi and J.P. Schimel. 1998. Ancient trees in Amazonia. Nature 391: 135 - 136.

Charnov, E.L. 1993. Life History Invariants: Some Explorations of Symmetry in Evolutionary Ecology. Oxford Univ. Press, Oxford. 
Clark, J.S., M. Silman, R. Kern, E. Macklin and J. HilleRisLambers. 1999. Seed dispersal near and far: patterns across temperate and tropical forests. Ecology 80: 1475-1494.

Clements, F.E. 1916. Plant Succession: An Analysis of the Development of Vegetation. Carnegie Institution of Washington, Publ. No. 242.

Drury, W.H. 1998. Chance and Change. Univ. California Press, Berkeley.

Drury, W.H. and Nisbet, I.C.T. 1973. Succession. J. Arnold Arbor. 54: 331-368.

Enquist, B.J., J.H. Brown and G.B. West. 1998. Allometric scaling of plant energetics and population density. Nature 395: 163-165.

Enquist, B.J., G.B. West, E.L. Charnov and J.H. Brown. 1999. Allometric scaling of production and life-history variation in vascular plants. Nature 401: 907-911.

Gleason, H.A. 1926. The individualistic concept of the plant association. Bull. Torrey Bot. Club 53: 1-20.

Gleason, H.A. 1927. Further views on the succession concept. Ecology 8: 299-326.

Gleeson, S.K. and D. Tilman. 1994. Plant allocation, growth rate and successional status. Func. Ecol. 8: 543-550.

Grime, J.P. 1977. Plant Strategies and Vegetation Processes. Wiley, Chichester.

Hengeveld, R. 1989. Dynamics of Biological Invasions. Chapman \& Hall, London.

Horn, H.S. 1971. The Adaptive Geometry of Trees. Princeton Univ. Press, Princeton.

Kimmins, J.P. 1997. Forest Ecology. $2^{\text {nd }}$ ed. Prentice Hall, Upper Saddle River, N.J.

Körner, C. (1991) Some often overlooked plant characteristics as determinants of plant growth: a reconsideration. Func. Ecol. 5: 162-173.

Lambers, H., F.S. Chapin and T.L. Pons. 1998. Plant Physiological Ecology. Springer, New York.

Lawton, J.H. and K.C. Brown. 1986. The population and community ecology of invading insects. Phil. Trans. R. Soc. Lond. Ser. B 314: 607-617.

Lerdau, M. and J. Gershenzon. 1997. Allocation theory and chemical defense. In: F. A. Bazzaz and J. Grace (eds.), Plant Resource Allocation. Academic Press, San Diego. pp. 265-277.

Levine, J.M. and C.M. D’Antonio. 1999. Elton revisited: a review of evidence linking diversity and invasibility. Oikos 87: 15-26.

Lodge, D.M. 1993. Biological invasions: lessons for ecology. Trends Ecol. Evol. 8: 133-137.

Loehle, C. 1988. Tree life histories: the role of defenses. Can. J. For. Res. 18: 209-222.

Lonsdale, W.M. 1999. Global patterns of plant invasions and the concept of invasibility. Ecology 80: 1522-1536.

McIntosh, R.P. 1999. The succession of succession: a lexical chronology. Bull. Ecol. Soc. Am. 80: 256-265.

Miles, J. 1979. Vegetation Dynamics. Chapman \& Hall, London.

Niklas, K.J. 1993. The allometry of plant reproductive biomass and stem diameter. Am. J. Bot. 80: 461-467.

Niklas, K.J. 1994. Plant Allometry. Univ. Chicago Press, Chicago.

Niklas, K.J. 1997. The Evolutionary Biology of Plants. Univ. Chicago Press, Chicago.
Odum, E.P. 1953. Fundamentals of Ecology. Saunders, Philadelphia.

Orlóci, L. and Orlóci, M. 1988. On recovery, Markov chains, and canonical analysis. Ecology 69: 1260-1265.

Poorter, H. and R. Villar. 1997. The fate of acquired carbon in plants: chemical composition and construction costs. In: F. A. Bazzaz and J. Grace (eds.), Plant Resource Allocation. Academic Press, San Diego. pp. 39-72.

Poorter, L. 1999. Growth responses of 15 rain-forest tree species to a light gradient: the relative importance of morphological and physiological traits. Func. Ecol. 13: 396-410.

Poorter, L. and M. Werger. 1999. Light environment, sapling architecture, and leaf display in six rain forest tree species. Am. J. Bot. 86: $1464-1473$.

Reekie, E.G. 1997. Trade-offs between reproduction and growth influence time of reproduction. In: F. A.Bazzaz and J. Grace (eds.), Plant Resource Allocation. Academic Press, San Diego. pp. 191-209.

Sibly, R.M. and J.F. Vincent. 1997. Optimality approaches to resource allocation in woody tissues. In: F. A. Bazzaz and J. Grace (eds.), Plant Resource Allocation. Academic Press, San Diego. pp. 143-159.

Silvertown, J.W. and J. Lovett Doust. 1993. Plant Population Biology. Blackwell, London.

Stearns, S.C. 1992. The Evolution of Life Histories. Oxford Univ. Press, Oxford.

Stiles, E.W. 1992. Animals as seed dispersers. In: M. Fenner (ed.), Seeds: The Ecology of Regeneration in Plant Communities. CAB International. Wallingford, U.K. pp. 87-104.

Tilman, D. 1988. Dynamics and Structure of Plant Communities. Princeton Univ. Press, Princeton.

Tilman, D. 1999. The ecological consequences of changes in biodiversity: a search for general principles. Ecology 80: 1455-1474.

van Hulst, R. 1988. Invasion models of vegetation dynamics. Vegetatio 69: 123-131.

van Hulst, R. 1992. From population dynamics to community dynamics: modelling succession as a species replacement process. In: D. C. Glenn-Lewin (ed.), Succession. Chapman \& Hall, London. pp. $188-214$.

van Hulst, R. 1997. Vegetation change as a stochastic process. Coenoses 12: 131-140.

Vitousek, P.M. 1994. Beyond global warming: ecology and global change. Ecology 75: 1861-1876.

West, G.B., J.H. Brown and B.J. Enquist. 1997. A general model for the origin of allometric scaling laws in biology. Science 276: 122-126.

West, G.B., J.H. Brown and B.J. Enquist. 1999. A general model for the structure and allometry of plant vascular systems. Nature 400: 664-667.

Westoby, M., E. Jurado and M. Leishman. 1992. Comparative evolutionary ecology of seed size. Trends Ecol. Evol. 7: 368-372.

White, P.S. and S.T.A. Pickett. 1985. Natural disturbance and patch dynamics: an introduction. In: S. T. A. Pickett and P.S. White (eds.), The Ecology of Natural Disturbance and Patch Dynamics. Academic Press, New York. pp. 3-13. 